\title{
A study of cleft lip/palate in a community in the South East of Ghana
}

\author{
Pius Agbenorku • Margaret Agbenorku • Abiba Iddi • \\ Fritz Abude • Ransford Sefenu • Paul Matondo • \\ William Schneider
}

Received: 11 June 2010/Accepted: 27 August 2010/Published online: 25 September 2010

(C) The Author(s) 2010. This article is published with open access at Springerlink.com

\begin{abstract}
The previous study in Wudoaba villages suggested that cleft lip and cleft palate (CL/CP) may be endemic in the Wudoaba cluster of villages in the Ketu South District of the Volta Region in South East Ghana. The study was to detect the prevalence of $\mathrm{CL} / \mathrm{CP}$ in the Wudoaba communities and to investigate the factors associated with the causes of this malformation in the area. Two different interview-based questionnaires were designed to collect data over a period of 3 days from March 27 to 29, 2006. A purposive and accidental random sampling technique was used in the administering of the various questionnaires to the respondents. Data collected
\end{abstract}

P. Agbenorku $(\bowtie)$

KNUST School of Medical Sciences,

Komfo Anokye Teaching Hospital,

Kumasi, Ghana

e-mail: pimagben@yahoo.com

M. Agbenorku

Health Education Unit,

Global Evangelical Mission Hospital,

Apromase, Ashanti Region, Ghana

A. Iddi

PIMA Hospital,

F. 57 Buokrom Estate,

Kumasi, Ghana

F. Abude $\cdot$ R. Sefenu $\cdot$ P. Matondo

South Tongu District Hospital,

Sogakope,

Volta Region, Ghana

W. Schneider

Interplast,

857 Maude Avenue,

Mountain View, CA 94043, USA were recorded and analyzed with SPSS version 17.0. A total 99 respondents, with a mean age of 55.0 years, were interviewed. Out of it, $57.6 \%(n=57)$ were related to their spouses: 54 first cousins and three other family relations. The prevalence of CL/CP is at least 6.3 per 1,000 people (i.e., 25/4,000). Majority $(56.0 \%, n=14)$ of the cleft cases were unilateral. Interviews revealed that genetic homogeneity and vitamin deficiencies in this community may be a causal factor for the high prevalence of CL/CP. This community provides clues suggesting that the magnitude of CL/CP may be larger than other studies and identifies the Wudoaba population as one that could be further studied to explore the underlying factors causing this congenital malformation.

Keywords Cleft lip/palate · Survey · Prevalence · Genetic homogeneity. Vitamins deficiency

\section{Introduction}

Cleft lip (CL; cheiloschisis) and cleft palate (CP; palatoschisis) are present at different frequencies in different cultures and races as well as countries. $\mathrm{CL}$ and/or palate $(\mathrm{CL} \pm \mathrm{P})$ is a congenital abnormality that is seen frequently around the world. On average, about one in every 500-750 live births results in a cleft [1]. Furthermore, in the USA, the prevalence of $C L \pm P$ is 2.2 to 11.7 per 10,000 births. Cleft palate alone (CPO) results in a prevalence rate of 5.5 to 6.6 per 10,000 births [2]. Cleft of the lip, palate, or both is one of the most common congenital abnormalities and has a birth prevalence rate ranging from $1 / 1,000$ to $2.69 / 1,000$ amongst different parts of the world [3].

Prevalence rates reported for live births for $\mathrm{CL} \pm \mathrm{P}$ and CPO vary within different ethnic groups. The highest 
prevalence rates for $\mathrm{CL} \pm \mathrm{P}$ are reported for Native Americans (3.74/1,000) and Asians (from 0.82/1,000 to $4.04 / 1,000$ ). Africans (from $0.18 / 1,000$ to $1.67 / 1,000$ ) have the lowest prevalence rates. Rate of occurrence of CPO is similar for Caucasians, Africans, North American natives, Japanese, and Chinese [3].

In Malawi, there is a reported low prevalence rate for $C L \pm P$, 0.7 per 1,000 live births [4]. Suleiman et al. [5] found that the prevalence rate of clefting among a group of Sudanese hospital newborns in the city of Khartoum is 0.9 per 1,000 live births. In Ghana, an earlier survey by our team in the Wudoaba communities revealed a $\mathrm{CL} / \mathrm{CP}$ prevalence of 5.0 per 1,000 people [6]. A retrospective review of CL and palate operations carried out at the Komfo Anokye Teaching Hospital (KATH) in Kumasi, Ghana, reported that a total of 344 patients were operated for CL and palate during the 5year period, i.e., 69 operations per year [7]. Most prevalence reports on $\mathrm{CL} / \mathrm{CP}$ had their data from hospitals, with relatively few studies done in communities [8]. In Ghana, the only community-base study on cleft was reported by Agbenorku et al. [6].

The development of the face is coordinated by complex morphogenetic events and rapid proliferative expansion, and is thus highly susceptible to environmental and genetic factors, rationalizing the high incidence of facial malformations. During the first 6 to 8 weeks of pregnancy, the shape of the embryo's head is formed. Genetic factors contributing to $\mathrm{CL} / \mathrm{CP}$ formation have been identified for some syndromic and non-syndromic cases, but knowledge about genetic factors that contribute to the more common isolated cases of CL/palate is still patchy [9]. The syndromic cases include the Van der Woude syndrome, which is caused by a specific variation in the gene IRF6 that increases the occurrence of these deformities threefold [9]. Another syndrome, Siderius X-linked mental retardation, is caused by mutations in the PHF8 gene (OMIM 300263) in addition to $\mathrm{CL} \pm \mathrm{P}$, with the symptoms such as facial dysmorphism and mild mental retardation. Stickler's syndrome, LoeysDietz syndrome, and Patau syndrome (trisomy 13) are all associated with $\mathrm{CL} \pm \mathrm{P}$ [10]. Non-syndromic cases include particular sequence variants in the genes IRF6, PVRL1, and MSX1 [11]. Genetic complexities are involved in the morphogenesis of the midface. If a person is born with a cleft, the chances of that person to have a child with a cleft, given no other obvious factor, rise to 1 in 14. Many clefts run in families, even though, in some cases, there does not seem to be identifiable syndromes present [12].

Environmental influences may also cause or interact with genetics to produce orofacial clefting. For instance, the catalytic activity of PHF8 depends on molecular oxygen [13]. In humans, fetal CL and other congenital abnormalities have also been linked to maternal hypoxia as caused by, for example, maternal smoking, maternal alcohol abuse, or some forms of maternal hypertensive treatment [14]. Other environmental factors that have been studied include the following: seasonal causes (such as pesticide exposure); maternal diet and vitamin intake; retinoids, which are members of the vitamin A family; anticonvulsant drugs; alcohol; cigarette use; nitrate compounds; organic solvents; parental exposure to lead; and illegal drugs (cocaine, crack cocaine, heroin, etc.). Current research continues to investigate the extent to which folic acid can reduce the incidence of clefting [14].

Local folklore has suggested that $\mathrm{CL} / \mathrm{CP}$ may be endemic in the Wudoaba cluster of villages in the Ketu South District of the Volta Region in South East Ghana [6]. A clue to this assertion is the local night market, a unique system of business in which food and other goods are bought and sold under the cover of total darkness, except the use of local kerosene "miniature lamps" [6]. In this study, the research team sought to determine the magnitude of CL/palate in Wudoaba and investigate the causal factors of $\mathrm{CL} / \mathrm{CP}$ in this area through interviews with household heads in the community.

\section{Materials and methods}

Study setting Wudoaba is a cluster of villages in the Volta Region of Ghana, under the Aflao Traditional Area, in the Ketu South District of the southeastern part of Ghana, close to the Ghana-Togolese boarder. The coordinates of Wudoaba are latitude, $060^{\circ} 09^{\prime} 21^{\prime \prime}$, and longitude, $010^{\circ} 05^{\prime}$ $48^{\prime \prime}$. It has a population of about 4,000 people, of which children form one-third [15]. Wudoaba was founded in 1816 by migrants from Viepe, a suburb of Aflao, who were in search of farming land.

The predominant occupation of the people is subsistent cassava and maize farming. They have a seasonal market for the production of "gari," which is made from cassava. During this season, people come from both far and near to patronize the only market which exists at night. There is only one basic school in the area with about 1,200 pupils. There is no health facility in the area; patients therefore travel to nearby Dzodze, Denu, or Aflao to assess health care. There are three chiefs in the area and one of them (who is the head chief) is the Secretary of the Aflao Traditional Council.

Data collection The consent of each respondent was sought before the interview commenced, after having obtained the necessary ethic clearance from the Ketu South Health Directorate through the Ketu South District Assembly and approval from the Paramount Chief of the Aflao Traditional Area. Two different interview-based questionnaires were designed: one to retrieve needed information from the chiefs 
and elders of the villages, and the second one was administered to household leaders of Wudoaba villages. The number of households in the Wudoaba villages was counted and mapped 2 weeks before the actual survey date, to enable the research team to prepare adequate logistics. The data were collected over a period of 3 days from March 27 to 29, 2006. A purposive and accidental random sampling technique was used in the administering of the various questionnaires to the respondents irrespective of age and social status. Data on CL/ CP recorded include the following: demographic data, causal factors, treatment, type of marriage, dynamics of the market, habits (lifestyle), predominant food, and societal influence on $(\mathrm{CL} \pm \mathrm{P})$ patients. The collected data were analyzed using SPSS version 17.0.

\section{Results}

Demographics of respondents

In the present study, an interview questionnaire was administered to heads of 99 households. Out of the total number of respondents, $61.6 \%(n=61)$ were males, and $38.4 \%(n=38)$ were females, with ages ranging from 20 to 70 years (mean age, 55.0 years; Fig. 1). Among these respondents, nearly $77.8 \%(n=77)$ had resided in the Wudoaba communities for more than 45 years (Fig. 2). Majority $(86.9 \%, n=86)$ of the respondents were farmers, while other respondents were traders, tailors, pastors, or masons by occupation (Fig. 3). Also, 36.4\% $(n=36)$ of the respondents had completed Senior High School and other forms of tertiary education (Fig. 4).

Prevalence of cleft lip and cleft palate in Wudoaba communities

To ensure that all respondents were made familiar with CL/ $\mathrm{CP}$ before answering questions about the conditions,

Age Distribution of Respondents

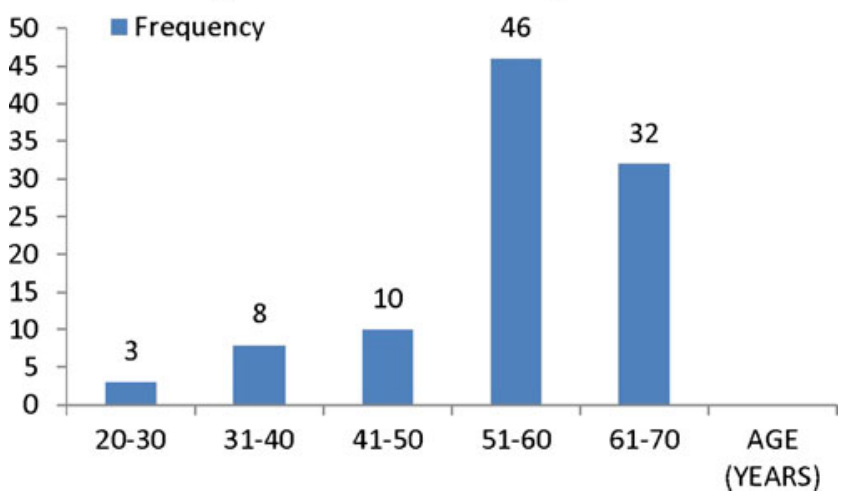

Fig. 1 Age distribution of respondents

\section{Period of Stay of Respondents in Wudoaba}

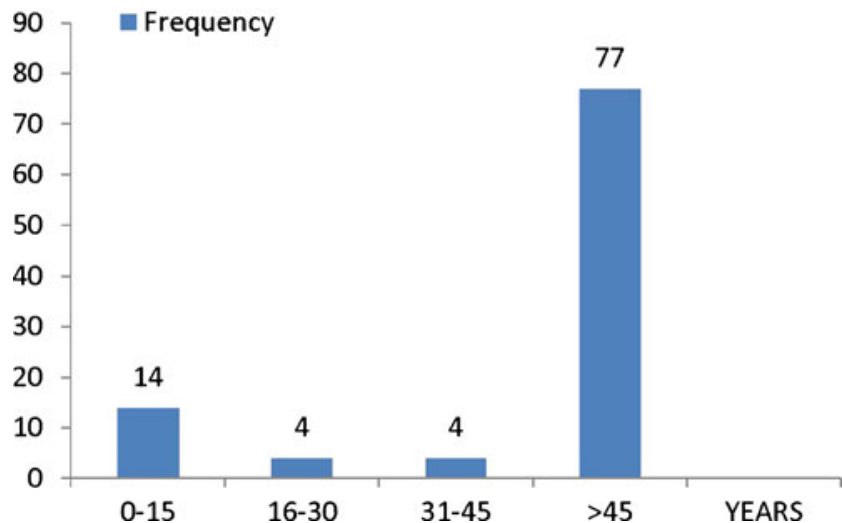

Fig. 2 Period of stay of respondents in Wudoaba

interviewers described the conditions and showed photographs of clefts to the respondents. To estimate the incidence of CL/CP in the Wudoaba communities, respondents were asked questions regarding the incidence of clefts in their household. During the study, the majority $(81.8 \%$, $n=81$ ) of the respondents reported they had no relatives with a CL/CP. However, $11.1 \%(n=11)$ of the respondents affirmed that at least one member of their household has $\mathrm{CL} / \mathrm{CP}$, and $7.1 \%(n=7)$ also confirmed that two household members had a CL/CP. Therefore, the total incidence of $\mathrm{CL} / \mathrm{CP}$ in the Wudoaba cluster of villages was reported to be 25 . The total population of this area is estimated at 4,000 inhabitants. Therefore, the estimated prevalence of CL/CP is at least 6.3 per 1,000 people $(0.625 \%, 1 / 160)$. Of the 25 cases of CL/CP reported, only one person had an isolated CP. Out of 14 unilateral CL/CP reported, $57.1 \%(n=8)$ were right-sided, and 42.9\% $(n=6)$ were left-sided. The other individuals had ( $\mathrm{CL} \pm \mathrm{P}$; Table 1).

\section{Occupation of Respondents}

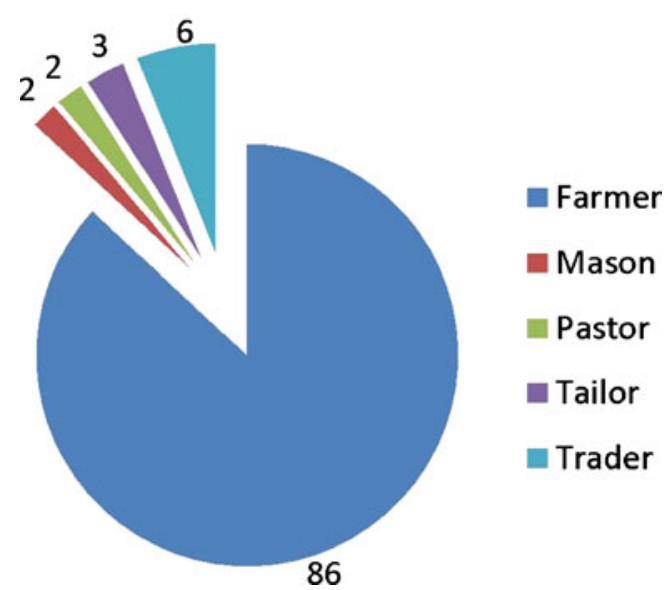

Fig. 3 Occupation of respondents 


\section{Level of Education of Respondents}

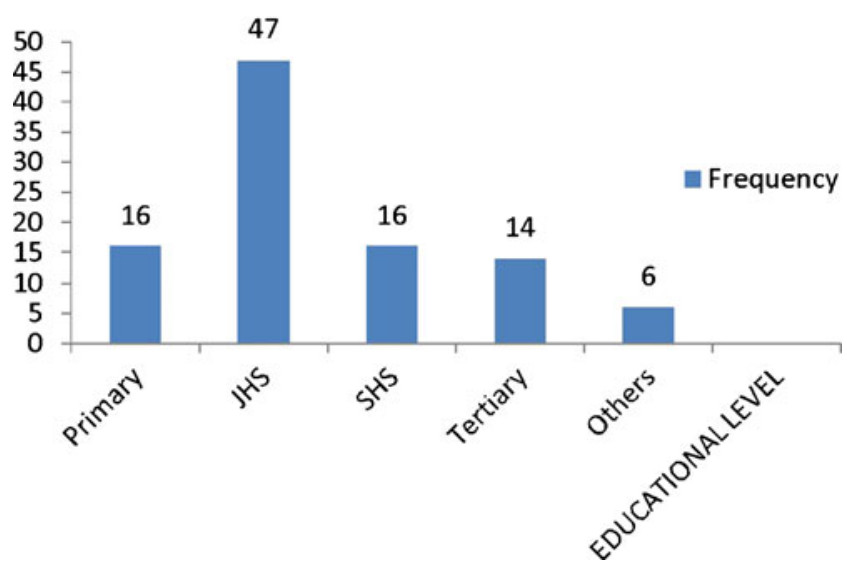

Fig. 4 Level of education of respondents

Possible causes of cleft lip/palate

Respondents were asked to estimate the number of consanguineous relationships in the households. Approximately $58.0 \%(n=57)$ of respondents reported being related to his or her spouse, out of which $94.7 \%(n=54)$ reported a first-cousin relationship to their spouse (Fig. 5).

Regular consumption of alcohol and smoking by at least one household member was reported by approximately $68.0 \%$ and $11.0 \%$ of respondents, respectively; the remaining $(21.0 \%)$ said members of their households do not take part in these habits.

Also, respondents were asked about their diet to assess possible nutritional deficiencies in the Wudoaba communities. Therefore, respondents were asked which foods constitute a majority of their households' diet. More than half $(59.6 \%, n=59)$ of the respondents reported that a combination of cassava and maize constituted the majority of the household's diet. Also, 36.4\% $(n=36)$ reported that their household primarily consumed maize; $1.0 \%(n=1)$ and $3.0 \%(n=3)$ reported that cassava and rice was the household's primary source of food, respectively.

Medical management of cleft lip/palate patients

Household heads were also asked questions pertaining access to and acceptance of medical treatment for house- hold members with $\mathrm{CL} /$ palate. Out of the 25 confirmed cases, $56.0 \%(n=14)$ reported having sought treatment for the cleft in the past (Fig. 6). Importantly, the results show that only five out of the 14 cleft patients had sought surgical treatment for their condition. The remaining patients were advised to seek another form of treatment.

Community perceptions of people with cleft lip/palate in Wudoaba

Respondents were asked about their beliefs in regard to what caused the cleft condition in their household member (s). Genetic factors and illness from the mother accounted for $17.2 \%(n=17)$ and $14.1 \%(n=14)$ of the responses, respectively. However, $40.4 \%(n=40)$ of respondents confirmed they did not know what caused the cleft (Fig. 7). In addition, $40.4 \%(n=40)$ of the respondents admitted that the society see people with cleft as outcast.

Questions about the night markets and others near their villages within the greater Wudoaba area to ascertain whether the high prevalence of clefts is related to the presence of night markets were also inquired. Almost $(91.2 \%, n=91)$ all respondents said they have bought or sold goods at the Wudoaba night market and added that they had encountered people with cleft(s) at the market. Furthermore, $75.6 \%(n=75)$ of people who patronized the night market reported that people with clefts are treated equally as normal people at the market.

\section{Discussion}

The prevalence of CL/CP in Africa had been reported to be the lowest when compared to other parts of the world [3]. Studies in Malawi and Sudan reported a low prevalence of 0.7 and 0.9 per 1,000 live births, respectively [4, 5]. The first community-based study in Ghana, by the same research team, reported a prevalence of 5.0 per 1,000 inhabitants of Wudoaba [6]. In this current study, a relatively high prevalence $(6.3$ per 1,000$)$ was recorded. The difference in prevalence could be attributed to greater awareness in the community created and free surgeries provided by our team in the first study. In addition, the results signify that a lot of community-based studies on $\mathrm{CL} / \mathrm{CP}$ should be encouraged.
Table 1 Characteristics of clefts among the reported cases $(N=25)$

\begin{tabular}{|c|c|c|c|c|c|}
\hline \multirow[t]{2}{*}{ Cleft } & \multirow[t]{2}{*}{ Number } & \multicolumn{2}{|c|}{ Occurrence } & \multicolumn{2}{|l|}{ Position } \\
\hline & & Complete & Incomplete & Unilateral & Bilateral \\
\hline Cleft lip & 17 & 11 & 6 & 9 & 8 \\
\hline Cleft palate & 1 & 0 & 1 & 1 & 0 \\
\hline Cleft lip/palate & 7 & 7 & 0 & 4 & 3 \\
\hline
\end{tabular}


Types of Consanguineous Relationship with Spouse $(\mathbf{N}=\mathbf{5 7})$

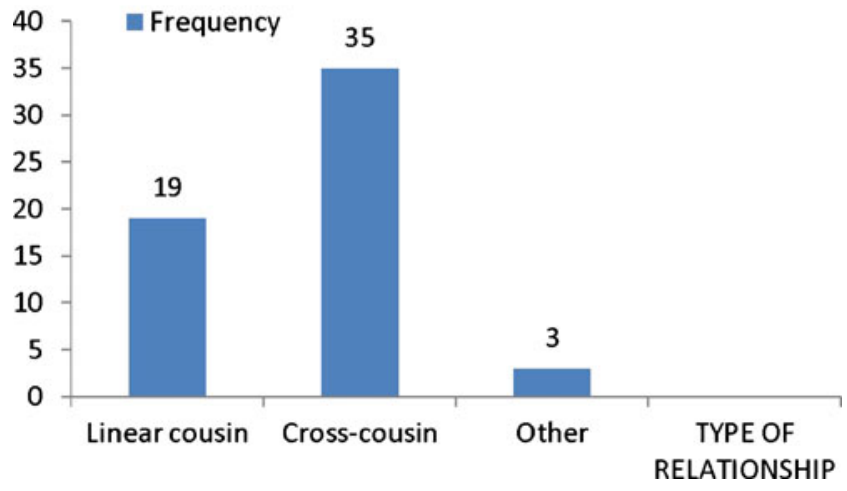

Fig. 5 Types of consanguineous relationship with spouse $(N=57)$

In order to reveal the actual prevalence rate especially in Africa, where the majority of adults are seen with $\mathrm{CL} / \mathrm{CP}$ [16]. This initial study was helped because the respondents were willing to contribute. Also, the majority $(56.0 \%, n=14)$ of the cleft cases reported during the study were unilateral. Donkor et al. [7] in their CL/CP study at KATH in Kumasi, Ghana, had similar results. These support the fact that unilateral cleft cases outnumber bilateral cases in Ghana.

In developed countries, with the advancement of medical services and awareness among patients, it is rare to find adults with un-operated CL and palate. However, the scenario is totally different in developing countries [17]. In our study, only $8.0 \%$ had their deformity treated surgically. However, Donkor et al. [7] reported in their study at KATH, Ghana, that there had been an increase in surgical treatment for $\mathrm{CL} / \mathrm{CP}$ cases. Our study correlates with the report of Murthy [16], since few CL/CP patients had surgical treatment. The difference with that of Donkor et al. may be due to the variations in study areas, since Kumasi is a regional capital where awareness of $\mathrm{CL} / \mathrm{CP}$ is

\section{Treatment sought by Cleft patients ( $N=14$ )}

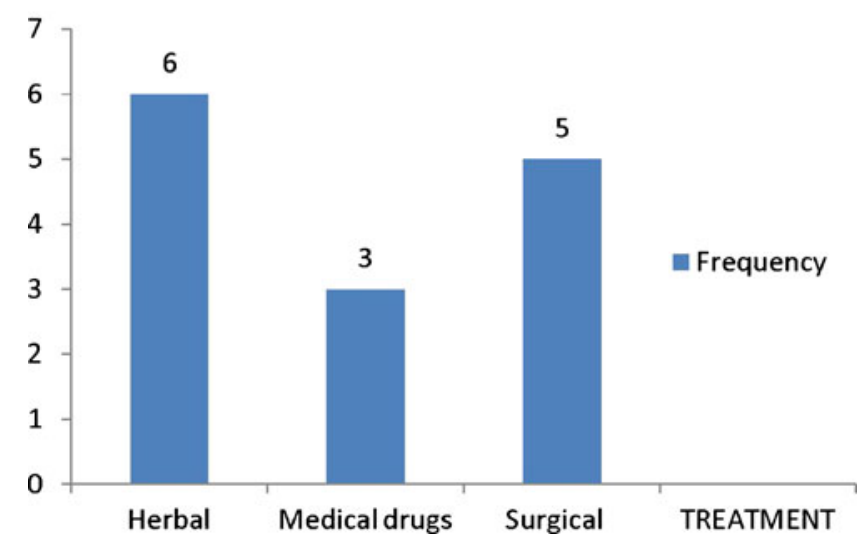

Fig. 6 Treatment sought by cleft patients $(N=14)$

\section{Respondents Perception on the Causes of Clefts}

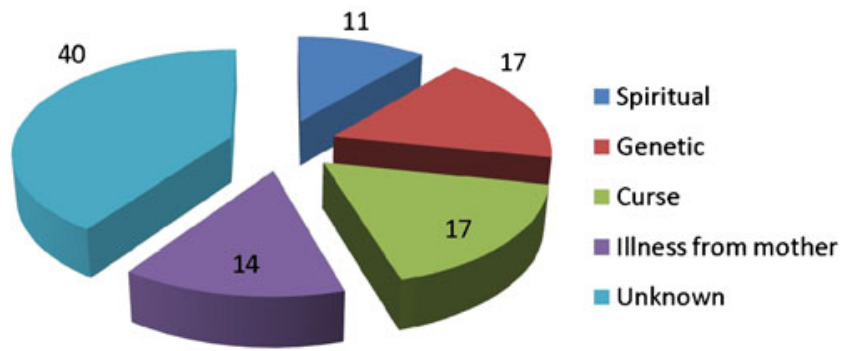

Fig. 7 Respondents perception on the causes of clefts

high, and free sponsored treatment is available for cleft patients.

Many clefts had been reported to run in families, even though in some cases, there does not seem to be an identifiable syndrome present [12]. The results of the study in terms of marital information show that a high number of the respondents were involved in consanguineous relationships: first-cousin relationship to their spouse. Zucchero [9] and others reported specific variation in the genes that increases the occurrence of these deformities threefold [911]. In addition, environmental influences may also cause, or interact with genetics to produce, orofacial clefting [13, $14,16]$. To verify the environmental influences in the cause of CL/CP, information on lifestyle was also recorded. The study results show that more than half of the respondents confirmed to have relatives who were alcoholics and few who smoke; however, no association was identified between the causes and lifestyle of the people. Hereditary material may therefore play important role in the cause of $\mathrm{CL} / \mathrm{CP}$ in the Wudoaba communities.

Vitamins such as folacin have a role in the cause of $\mathrm{CL} /$ $\mathrm{CP}$ [14]. Lack of folic acid (also known as vitamin $\mathrm{B}_{9}$ or folacin), leading to folate deficiency, can result in many health problems, most notably, defects in developing embryos [18, 19]. Leafy vegetables, fruits, vegetables, breakfast cereals, liver, and liver products are rich sources of folate [20]. Assessing the diets of the people, the results show that the main food sources were cassava and maize. This could be an associated factor in CL/CP.

Although few respondents had knowledge about genetic factors of $\mathrm{CL} / \mathrm{CP}$, the study revealed that most of the people with $\mathrm{CL} \pm \mathrm{P}$ were seen as outcasts in their societies. Issues related to the night market were confirmed by majority and admitted that there the "outcasts" and other people were treated equally. Night market periods could be very dangerous; since proper lighting systems are not available at the place, there is risk of being bitten by snakes. Stigmatization faced by people living with $\mathrm{CL} / \mathrm{CP}$ in the societies of Wudoaba is serious, and this could affect the younger ones academically and psychologically, since they 
would not be courageous enough to participate in school activities.

\section{Conclusion}

The prevalent rate of CL/CP in Wudoaba communities was alarming. This community provides clues, suggesting that the magnitude of CL/CP may be larger than other studies, and identifies the Wudoaba population as one that could be further studied to explore the underlying factors causing this congenital malformation.

Genetic and vitamins deficiency-related factors may be associated in the causes of CL/CP. Funds to treat all the patients in free surgical services and research on genetic and nutritional links in the cleft population in the area should be embarked by all stakeholders in and outside Ghana.

Acknowledgements We are grateful to Interplast, a US nongovernmental organization that partially sponsored us financially in the sum of US $\$ 2,000.00$ to conduct this study.

We also wish to thank the Medical Records Department staffs, especially Mr. Nelson Srekumah and the rotation nursing staffs of the South Tongu District Hospital, Sogakope, for the tremendous interest they showed in this research thereby assisting in the field data collection process in the Wudoaba villages. Similarly, we acknowledge the secretarial duties of Mr. Thomas Diby who helped in putting this manuscript together.

We are also grateful to the Ketu South Health Directorate, the Ketu South District Assembly, and the Paramount Chief of the Aflao Traditional Area for permitting us to conduct this survey in the area.

Open Access This article is distributed under the terms of the Creative Commons Attribution Noncommercial License which permits any noncommercial use, distribution, and reproduction in any medium, provided the original author(s) and source are credited.

\section{References}

1. Peterson-Falzone SJ, Hardin-Jones MA, Karnell MP (2001) Cleft palate speech, 3rd edn. Mosby, St. Louis, p 152

2. Forrester MB, Merz RD (2004) Descriptive epidemiology of oral clefts in a multiethnic population, Hawaii, 1986-2000. Cleft Palate-Craniofac J 41(6):622-628

3. McLeod NMH, Arana-Urioste ML, Saeed NR (2004) Birth prevalence of cleft lip and palate in sucre, Bolivia. Cleft PalateCraniofac J 41(2):195-198
4. Msamati BC, Igbibi PS, Chisi JE (2000) The incidence of cleft lip. Cleft palate, hyrocephalus, and spina bifida at Queen Elizabeth Central Hospital, Blantyre, Malawi, Central Africa. J Med 46 (11):292-296

5. Suleiman AM, Hamzah ST, Abusalab MA, Samaan KT (2005) Prevalence of cleft lip and palate in a hospital-based population in Sudan. Int J Paediatr Dent 15:185-189

6. Agbenorku P, Agbenorku M, Sefenu R, Matondo P, Osei D (2007) Endemicity of cleft lip/palate in a rural community in South-East Ghana. J Sci Technol 27(1):45-50

7. Donkor P, Bankas DO, Agbenorku P, Plange-Rhule G, Ansah SK (2007) Cleft lip and palate surgery in Kumasi, Ghana: 2001-2005. J Craniofac Surg 18(6):1376-1379

8. Butali A, Mossey PA (2009) Epidemiology of orofacial clefts in Africa: methodological challenges in ascertainment. Pan Afr Med J 1(2):5-14

9. Zucchero TM (2004) Interferon regulatory factor 6 (IRF6) gene variants and the risk of isolated cleft lip or palate. N Engl J Med 351:769-780

10. Siderius LE, Hamel BC, van Bokhoven H et al (2000) X-linked mental retardation associated with cleft lip/palate maps to Xp11.3q21.3. Am J Med Genet 85(3):216-220

11. Cox TC (2004) Taking it to the max: the genetic and developmental mechanisms coordinating midfacial morphogenesis and dysmorphology. Clin Genet 65(3):163-176

12. Millicovsky G, Johnston MC (1981) Hyperoxia and hypoxia in pregnancy: simple experimental manipulation alters the incidence of cleft lip and palate in CL/Fr mice. Proc Natl Acad Sci USA 78 (9):5722-5723

13. Loenarz C, Ge W, Coleman ML et al (2009) PHF8, a gene associated with cleft lip/palate and mental retardation, encodes for an $\mathrm{N}$ \{varepsilon\}-dimethyl lysine demethylase. Hum Mol Genet 10(5):109-114

14. Hurst JA, Houlston RS, Roberts A, Gould SJ, Tingey WG (1995) Transverse limb deficiency, facial clefting and hypoxic renal damage: an association with treatment of maternal hypertension? Clin Dysmorphol 4:359-363

15. Ghana Statistical Service (2000) National population censusdemographic records of Ketu South District, Volta Region of Ghana. Ghana Statistical Service, Ghana

16. Shi M, Wehby GL, Murray JC (2008) Review on genetic variants and maternal smoking in the etiology of oral clefts and other birth defects. Birth Defects Res C 84(1):16-29

17. Murthy J (2009) Management of cleft lip and palate in adults. Indian J Plast Surg 42:116-122

18. Weinstein SJ (2003) Null association between prostate cancer and serum folate, vitamin B6, vitamin B12, and homocysteine. Cancer Epidemiol Biomark Prev 12:1271-1272

19. Wilcox AJ, Lie RT, Solvoll K et al (2007) Folic acid supplements and risk of facial clefts: national population based case-control study. BMJ 334:464-471

20. Dietrich M, Brown CJ, Block G (2005) The effect of folate fortification of cereal-grain products on blood folate status, dietary folate intake, and dietary folate sources among adult non-supplement users in the United States. J Am Coll Nutr 24:266-274 